\title{
PRÁTICAS DE LABORATÓRIO: UMA ESTRATÉGIA PARA O ENSINO DE FÍSICA
}

\section{LABORATORY PRACTICES: A STRATEGY FOR PHYSICAL EDUCATION}

Douglas Henrique de Oliveira Braz, Deuber Lincon da Silva Agostini.

Universidade Estadual Paulista - UNESP. Pós - graduação em Mestrado Profissional em Ensino de Física, Presidente Prudente, SP, Brasil.

e-mail: douglashob@live.com

RESUMO - Este artigo destina-se ao estudo das práticas de laboratório como uma estratégia para o ensino de Física na elaboração de roteiros experimentais que venham aperfeiçoar o processo de aprendizagem. Durante algumas análises nos roteiros experimentais presente no currículo do estado de São Paulo realizou-se uma etapa de classificação em três critérios quanto sua disposição, suas atividades e suas metodologias presentes, após esse processo, efetuaram-se uma nova elaboração com novos critérios no mesmo experimento. Essas estratégias em roteiros direcionados e problematizados geram questões desafiadoras aos discentes desconstruindo o saber presente para construir um novo saber, os tornados protagonistas de sua aprendizagem. Quando os discentes são forçados a discutir algo novo, revendo conceitos já estabelecidos em si, começam a perceber que o conhecimento existente não é o suficiente para resolver os problemas proposto. Esse processo forneceu aos discentes autonomias e liberdade para absorver aquilo que é importante pra si.

Palavras-chave: laboratório; corrente elétrica; atividade experimental.

Recebido em: 25/07/2017

Revisado em: 04/08/2017

Aprovado em: 07/08/2017
ABSTRACT - This article aims to study laboratory practices as a strategy for the teaching of physics in the elaboration of experimental scripts that will improve the learning process. During some analyzes in the experimental scripts present in the curriculum of the state of São Paulo, a classification stage was carried out in three criteria regarding its disposition, its activities and its present methodologies, after this process, a new elaboration was made with new criteria in the same one experiment. These strategies in directed and problematized scripts generate challenging questions for the students, deconstructing the present knowledge to build a new knowledge, the protagonists of their learning. When students are forced to discuss something new, reviewing already established concepts themselves, they begin to realize that existing knowledge is not enough to solve the problems proposed. This process gave the students autonomy and freedom to absorb what is important to them.

Keywords: laboratory; electric current; experimental activity. 


\section{INTRODUÇÃO}

As atividades experimentais vêm sendo aplicadas nas escolas a mais de um século, exercendo papel fundamental no processo de ensino e aprendizagem colaborando para que o aluno desenvolva a capacidade de explorar os mais diversos conceitos físicos aplicando-os em seu dia-adia. A principal questão se encontra na total elaboração e aplicação de alguns conceitos que são desenvolvidos na vida acadêmica, mas, será que todos os experimentos são viáveis e eficazes?

Segundo Marandino, Selles e Ferreira (2009) “a experimentação contribui para melhorar a qualidade no ensino, principalmente por meio de situações de confronto entre as hipóteses dos alunos e as evidências experimentais". As aulas ministradas nos laboratórios melhoram a qualidade do ensino, uma vez que no momento em que os alunos manuseiam os materiais a serem utilizados nos experimentos ocorre uma conexão com a realidade, saindo do campo de abstração onde apenas as teorias são apresentadas.

Segundo o currículo de Ciências da Natureza (ciências, física, química e biologia) do estado de São Paulo (SEE, 2010) sua principal característica encontra-se em despertar o olhar investigativo do aluno, aprimorando sua competência e percepção de vida. Ao analisar a matriz curricular do
Estado em sua proposta apostilada, notamos que alguns conceitos físicos, como circuitos elétricos, ondas eletromagnéticas, óptica e ondas, por exemplo, são apresentados no $8^{\circ}$ e $9^{\circ}$ ano do ensino fundamental, tais conhecimentos são aprimorados e expandidos no $2^{\circ}$ e $3^{\circ}$ ano do ensino médio, em física. O reconhecimento e a compreensão de um circuito elétrico, por exemplo, permitem identificar as características elétricas básicas dos aparelhos, os perigos e cuidados a serem tomados ao trabalhar-se com uma rede elétrica.

Por volta do século XVII a humanidade apreendeu como produzir corrente elétrica, através do fluxo contínuo de partículas eletrizadas conduzidas por fios metálicos. $\mathrm{Na}$ constituição da corrente elétrica encontramos elétrons que se movem ao longo de todo o fio, ocorrendo com tamanha facilidade porque nos átomos dos metais os elétrons estão mais distantes do núcleo, ocorrendo uma ligação fraca entre eles, formando os elétrons livres. Em qualquer material com boa condução elétrica os elétrons estão livres, porém, os elétrons se movimentam de maneira desordenada. Ao inserir uma força elétrica os elétrons começam a sofrer uma ordem sendo percorrido por um caminho, este movimento ordenado recebe o nome de corrente elétrica. 
A descoberta da corrente elétrica abriu as portas para muitos pesquisadores permitindo uma série de estudos, por exemplo, à invenção dos motores elétricos e dos dínamos, sendo de grande importância na segunda fase da Revolução Industrial, ocorrida em meados do século XIX. Querendo utilizar os benefícios da corrente elétrica alguns limites se fizeram necessários, por exemplo, como não tomar um choque ao trabalhar com os condutores elétricos, como conduzir a corrente elétrica por longas distâncias sem danificar os fios e a rede, quais matérias suportam uma grande quantidade de intensidade elétrica, enfim questões como essa aguçaram a curiosidade dos pesquisadores da época.

Até meados do século XIX, os fenômenos elétricos e magnéticos eram considerados distintos um dos outros, porém, a partir dessa época uma série de experimentos comprovou a compatibilidade de ambas, Sampaio e Calçada (2005) salientam "devido à evolução das pesquisas em curso, foi possível constatar que esses dois tipos de efeitos são produzidos por uma mesma entidade: a carga elétrica". Esses questionamentos e direcionamentos que nortearam a evolução dos estudos no ramo do eletromagnetismo aconteceram pelo método da tentativa e erro, onde físicos e estudiosos afins aplicaram suas teorias em uma prática 'O experimento'.
Com os avanços nos estudo do currículo de ciências da natureza nos últimos anos, ocorreu uma considerável inclusão de vários experimentos em todos os conceitos físicos. Ao analisarmos o material apostilado do Estado, não podemos mais olhar para o laboratório como um lugar provido de instalações, aparatos e produtos de aplicações ou desenvolvimentos das atividades, mas sim como uma estratégia de ensino, sendo uma sala de aula atrativa em sua aplicabilidade e eficácia no processo de ensino aprendizagem.

Inicialmente iremos estudar os experimentos inseridos no material apostilado, proposto no currículo estadual de ciências da natureza. Buscando adequar os experimentos de maneira a melhorar a qualidade de ensino. Em um segundo momento, todos os experimentos selecionados serão qualificados e classificados em três níveis (quanto à disposição, quanto às atividades e quanto à metodologia de ensino). Enriquecendo todo o roteiro experimental a ser seguido tanto pelo docente, quanto ao discente ou qualquer pessoa que venha a obter acesso a esse material.

\section{METODOLOGIA}

Brodin (1978) articula "O laboratório é o elo que falta entre o mundo abstrato dos pensamentos e idéias e o mundo concreto 
das realidades físicas. O papel do laboratório é, portanto, o de conectar dois mundos, o da teoria e o da prática", no que se diz respeito às atividades experimentas que venham a ser culminantes com os conteúdos programados, exige uma necessidade em que o experimento seja minuciosamente planejado e arquitetado a fim de atingir diretamente o discente, despertando um olhar crítico e investigativo durante a práxis, colocando-o como protagonista da construção de seu conhecimento.

Ao introduzir o laboratório como ferramenta didática, conduzimos os alunos em um caminho importantíssimo, o da tentativa e erro. Propomos que ambos utilizem dessa ferramenta com auxílio da intuição para a construção do experimento, assim como, os engenheiros não praticam a física teórica o tempo todo no papel e caneta, mas ao possuírem os conhecimentos adquiridos ao longo de sua práxis, tornam-se profissionais intuitivos. $\mathrm{O}$ ato de arquitetar, elaborar e produzir um material através das interações entre os conhecimentos adquiridos no âmbito tradicional faz que com haja uma confusão mental, levando o discente a desconstruir para construir, consolidando e ao mesmo tempo dando significado ao que sempre foi um mistério para sua vida.

Ao refletirmos sobre essas práticas pedagógicas, nos deparamos com a teoria de
David Ausubel (2000), estabelecendo uma visão cognitivista no processo de aprendizagem, no momento da organização e assimilação do alicerce cognitivo do indivíduo. Essa idiossincrasia passa por uma hierarquia de conceitos abstratos até sua formalização conceitual estruturada na experiência adquirida através das interações no processo de planejamento e produção.

Para que haja um melhor desempenho do discente no processo de ensino aprendizagem no desenvolvimento da aula experimental, é de fundamental importância que 0 docente tenha estruturado sua aula experimental em um roteiro claro e objetivo, sendo transparente à leitura dos alunos. As atividades precisam ser direcionadas formalizando uma seqüência didática verossímil em sua aplicação. No processo de estruturação de qualquer aula experimental, devemos nós atentar às disposições (objetivos) a serem almejados e consolidados pelos discentes, quanto às atividades (montagem) que devem estar atreladas aos objetivos, e por fim, o mais importante, a meu ver, a metodologia (didática) a ser aplicada.

O primeiro passo consiste na classificação do roteiro experimental em estruturado (aquele que fornece instruções detalhadas do roteiro, o qual será seguido à risca), e não estruturada (apresenta os objetivos, porém, deixa a elaboração a cargo 
do discente). O segundo passo classificou-se em motivacional (despertando o interesse do discente), funcional (realizada com matérias de fácil acesso), instrucional (o aprendizado ocorre por um processo de instruções), e por fim, epistemológica (o aprendizado ocorre por meio da construção).

O terceiro passo trata-se dos aspectos metodológicos, classificou-se em demonstrativo (objetos do cotidiano) ou quantitativo com aparatos simples (equipamentos não precisos na utilização de medições), quantitativos com aparatos sofisticados (equipamentos produzidos por empresas especializadas), problematizadores (aqueles que geram hipóteses), portadores de necessidades especiais (adaptação aos portadores das necessidades, como prescritos na legislação vigente).

\section{ATIVIDADE EXPERIMENTAL Roteiro 1 - Proposto pelo Currículo}

\section{Experimente 1: “Aprendendo a acender uma}

\section{lâmpada: o primeiro circuito".}

1. O que acontece quando apertamos um interruptor de luz? Por que a lâmpada acende? Registre suas idéias no caderno.

Material: Um pedaço de fio cabinho (fio de telefone) de $40 \mathrm{~cm}$ de comprimento; Uma lâmpada de $3 \vee$ (aquelas de lanterna); Duas pilhas (1,5 v cada); Fita adesiva; Tesoura sem ponta.

Procedimento:
1. De posse desse material, faça a lâmpada acender. A cada tentativa, você deve desenhar o arranjo e dizer se a lâmpada acendeu ou não.

2. Compare os desenhos que você fez com as montagens apresentadas na imagem a seguir. Quais desses arranjos você fez? Em qual (is) deles a lâmpada acendeu?

Figura 1. Experimento 1. Fonte: Caderno do aluno Ciências. Ensino fundamental - Anos finais. \&a série / 8o ano. (SEE, 2017, V. 2. P. $65)$.

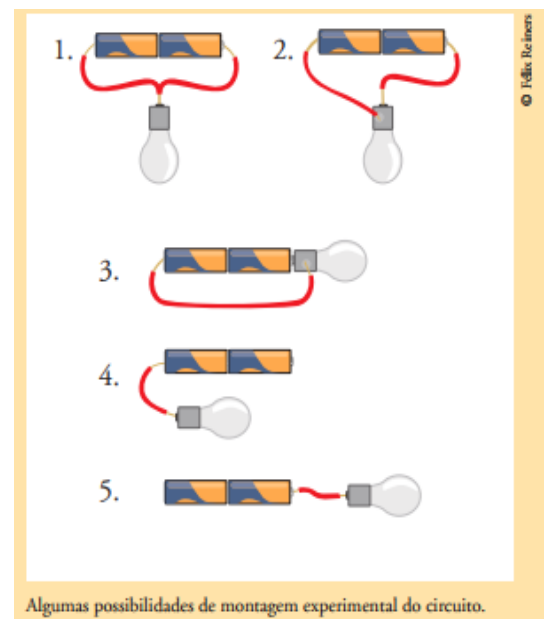

3. Depois de realizada a experiência, responda: Por que a lâmpada acende quando acionamos o interruptor de luz? E por que ela apaga quando o acionamos novamente?

\section{Experimento 2: "Construindo uma} luminária: abrindo e fechando um circuito". Material: Uma lâmpada de lanterna de 3 V la mesma usada na experiência anterior); Fios cabinho (fios de telefone); Duas tachinhas; Tiras de metal de uma lata de refrigerante; Lixa; Duas pilhas (1,5 V cada); 
Fita adesiva; Uma base de madeira ou papelão grosso; Tesoura sem ponta; Martelo.

Figura 2. Experimento 1. Fonte: Caderno do aluno Ciências. Ensino fundamental - Anos finais. \&a série / 8o ano. (SEE, 2017, V. 2. P. 65).

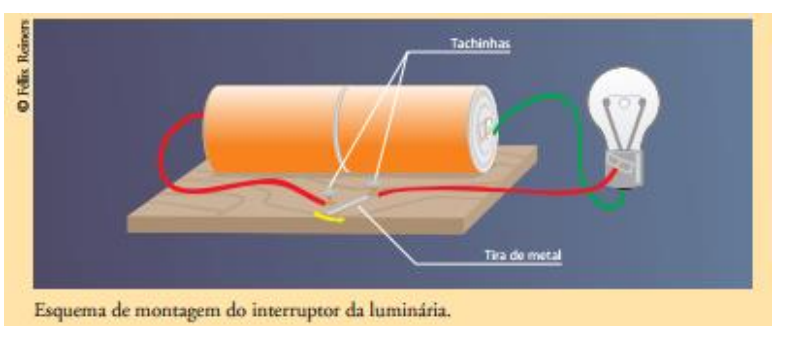

Procedimentos:

1. Desencape as extremidades dos fios.

2. Prenda uma pilha à outra com fita adesiva (pólo positivo encostado no pólo negativo).

3. Prenda com fita adesiva a ponta de um fio em um dos lados da dupla de pilhas e a outra ponta na lâmpada (veja o fio de cor verde na figura).

4. Prenda com fita adesiva uma ponta do fio na lâmpada e enrole a outra ponta na tachinha (veja o fio vermelho, na figura).

5. Faça o mesmo com a pilha: prenda uma ponta do fio na pilha e a outra ponta na segunda tachinha.

6. Recorte uma pequena tira de alumínio da lata. Use a lixa para retirar da tira a camada de verniz (que é isolante).

7. Espete uma das tachinhas na lâmina metálica e enfie as duas tachinhas com os fios já enrolados na base, deixando-as um pouco separadas.
Roteiro 2

Experimento 1: “Aprendendo a acender uma lâmpada: o primeiro circuito".

Objetivos: Acender a lâmpada usufruindo dos materiais fornecidos; Analisar as diferentes tentativas de ligação; Testar suas hipóteses; Perceber o conceito de corrente elétrica.

Discussão: Por que a Lâmpada acende? Ela faz parte do circuito?

Materiais: Fios cabinhos; Lâmpada de 3v; Pilhas de 1,5v cada; Fita adesiva; Tesoura sem ponta.

Experimento 2: “Construindo uma luminária: abrindo e fechando um circuito". Objetivos: Acender e apagar a lâmpada; Observar e analisar a função de cada material; Analisar a função de um interruptor; Estudar o que ocorre com o abrir e fechar de um circuito.

Discussão: Por que a lâmpada apaga e acende no sistema? Qual a função da lamina metálica no sistema?

Materiais: Lâmpada de 3v; Fios cabinhos; Duas tachinhas; Alumínio de lata de refrigerante; Lixa; Pilhas de 1,5v cada; Fita adesiva; Uma base de madeira ou papelão grosso; Tesoura sem ponta; Martelo.

\section{RESULTADOS}

Retomando o conceito elétrico do $8^{\circ}$ anos, na situação de aprendizagem seis do volume dois, temos dois roteiros 
experimentais "Aprendendo a acender uma lâmpada: o primeiro circuito" e na sequência "construindo uma luminária: abrindo e fechando um circuito", o próprio currículo traz em sua plataforma roteiros direcionados em uma disposição não estruturada e estruturada. Uma atividade funcional e instrucional. Quanto à metodologia presente no experimento do currículo, podemos classificá-lo como demonstrativo e quantitativo com aparatos simples.

Utilizando o mesmo experimento prenunciado no material apostilado, quando efetuamos uma nova classificação, adulteramos todo o roteiro, visto que, ao mudar a disposição do roteiro, temos um novo caminho a prosseguir. Com um novo objetivo traçado, nossos roteiros serão não estruturados, instrucional e epistemológico, pois seu conhecimento será construído ao mesmo tempo. No que diz respeito à metodologia, ela estará atrelada no campo quantitativo com aparatos simples e na problematização.

A sala é composta por treze discentes, sendo separada em três grupos de três integrantes e um grupo de quatro integrantes. Todos os integrantes dispunham dos mesmos conhecimentos teóricos ministrados em aula e dos mesmos materiais, a única diferença se concentra que cada grupo receberá modelos de roteiros diferentes, o proposto pelo currículo (roteiro
1), e o roteiro elaborado pelos critérios citados acima como não estruturado (roteiro 2). Os grupos um e dois ficaram designados com o roteiro 1, já os grupos três e quatro ficaram a cargo do roteiro 2. No desdobrar do tempo, cada grupo encontrou suas adversidades e impasses que precisavam ser resolvidas através da investigação, observação e intuição, em alguns momentos, houve aqueles que recorreram a livros, a web site apropriados, vídeo aulas, enfim, procuraram outros meios de obter as informações que precisavam, e até mesmo alguns conceitos que não haviam compreendidos foram assimilados.

O roteiro 1, designado aos grupos um e dois, foram elaborados em um período de tempo menor, que os demais. Os discentes seguiram todas as instruções elencadas no roteiro experimental, embora tenham se deparado com alguns empecilhos, sua maior dificuldade encontrou-se na interpretação a ser seguida. Ao final do experimento, com produto final elaborado, os membros do grupo sabiam explicar o que tinham feito, devido à sequência que seguiram, suas explicações foram bem automáticas em relação ao circuito elétrico, nada além do básico esperado. 0 roteiro 2 , destinado aos grupos três e quatro, foi necessário mais tempo a ser desenvolvido, notou-se que neste roteiro não estruturado os alunos necessitaram de mais informações para 
chegar ao seu produto final, como não tinham uma sequência de itens a serem seguidos criteriosamente, ao invés disso, tiveram que explorar todas as possibilidade possíveis e seguir sua intuição para montar o circuito elétrico.

\section{DISCUSSÃO}

No início desta pesquisa alguns objetivos foram traçados, entre eles 0 principal era realizar um estudo dos objetivos e metodologias presentes nos roteiros experimentais estabelecidos no material apostilado e, com base neles, classificando e modificando sua proposta inicial de maneira a melhorar sua aplicação e resultados.

Observamos que os discentes responsáveis pelo roteiro de experimento não estruturado, gastaram mais tempo para alcançarem seu produto final, todo esse tempo aplicado gerou um acúmulo de experiências pelo método da tentativa e erro, em um seminário realizado em sala sete dias após aula experimental, os alunos que tiveram de explorar todas as hipóteses certas ou erradas, demonstraram domínio dos conceitos sobre circuito elétrico, consolidando seu aprendizado de maneira significativa.

Em contra partida, os discentes incumbidos do roteiro de experimento estruturado, obtiveram seu produto final em menor tempo, durante o seminário os discentes mal recordaram os conceitos aplicados na elaboração do seu produto final, recordaram-se dos materiais utilizados e que houve uma sequência, entretanto não conseguiram enumerar a ordem seqüencial utilizada, muito menos as maneiras que construíram o circuito elétrico recorreram à justificativa pragmática (NASSER; TINOCO 2003), atestando que o circuito foi montado a partir da seqüência estabelecida, contudo salientou-se que todos os discentes conseguiam identificar a diferença de um circuito simples, e o acontece com um circuito quando se está fechado e aberto.

\section{CONCLUSÃO}

Muitos estudos se fizeram e se faz até os dias atuais no processo de ensino e aprendizagem, cada qual á seu modo, seu estilo, seja ele na área cognitiva, afetiva ou psicomotora, temos excelentes referências a seguir. Deste modo atrelou-se nossa visão, tanto de professor quanto de pesquisador, que o ápice da aprendizagem significativa, está na aplicação da teoria junto à prática, sendo uma delas a prática laboratorial, sendo um discente errante e consciente que o seu saber depende da sua própria autonomia.

\section{AGRADECIMENTOS}

Agradeço a Sociedade Brasileira de Física (SBF), e a Profa. Dra. Agda Eunice de 
Souza Albas pela oportunidade e apoio na elaboração e colaboração desta pesquisa.

\section{REFERÊNCIAS}

BRODIN, G. The role of the laboratory in education of industrial physicists and electrical engineers, 1978.

MARANDINO, M.; SELLES, S. E.; FERREIRA, M. S. Ensino de Biologia: histórias e práticas em diferentes espaços educativos. São Paulo: Cortez, 2009.

AUSUBEL, D. P. Aquisição e Retenção de Conhecimento: Uma Perspectiva Cognitiva. Tradução Lígia Teopisto. Editora Paralelo, Lisboa, 2000.

NASSER, L.; TINOCO, L. A. A. Argumentação e provas no ensino de matemática. 2. ed. Rio de Janeiro: UFRJ, 2003.

SAMPAIO, J.L.; CALÇADA, C.S. Universo da Física 3: ondulatória, eletromagnetismo, física moderna. 2. Ed. São Paulo: Atual, 2005.

SEE, São Paulo (Estado) Secretaria da Educação. "Currículo dou Estado de São Paulo: Ciências da Natureza e suas Tecnologias". Secretaria da Educação; coordenação geral: Maria Inês Fine; coordenação da área: Luís Carlos Menezes. São Paulo, 2010.

SEE, São Paulo (Estado) Secretaria da Educação. Material de Apoio ao Currículo do Estado de São Paulo. Caderno do Aluno. Ciências. Ensino Fundamental - Anos Finais. 7a série / 8o ano. V.2. São Paulo: Nova Edição, 2017. 